\title{
Experimental Investigation of Multihazard Resistant Bridge Piers Having Concrete-Filled Steel Tube under Blast Loading
}

\author{
Shuichi Fujikura, M.ASCE${ }^{1}$; Michel Bruneau, M.ASCE²; and Diego Lopez-Garcia ${ }^{3}$
}

\begin{abstract}
This paper presents the development and experimental validation of a multizard bridge pier concept, i.e., a bridge pier system capable of providing an adequate level of protection against collapse under seismic and blast loading (but not acting simultaneously). A multicolumn pier-bent with concrete-filled steel tube (CFST) columns is the proposed concept, and the adequacy of this system is experimentally investigated under blast loading. This paper describes simplified blast analysis, multihazard design of bridge piers, and blast experimental program and results. Additionally, the results from the blast experiments are compared with the results from the simplified method of analysis considering an equivalent single degree of freedom system having an elastic-perfectly plastic behavior. It is found that prototype bridge CFST columns can be designed to provide both satisfactory seismic performance and adequate blast resistance. It is also shown that the CFST columns exhibited a ductile behavior under blast load in a series of tests at 1/4 scale. Maximum deformation of the columns could be calculated using simplified analysis considering a factor to account for the reduction of pressures on the circular column and determined from this experimental program.
\end{abstract}

DOI: 10.1061/(ASCE)1084-0702(2008)13:6(586)

CE Database subject headings: Blasting; Blast loads; Bridges, piers; Columns; Steel.

\section{Introduction}

Terrorist attacks such as the one on the Alfred P. Murrah Federal Building in Oklahoma City (1995) and the one on the tallest towers of the World Trade Center in New York City (2001) are examples of the fact that the destruction of civil engineering structures has become one of the means employed by terrorists to achieve their objectives. Although bridge structures in North America have not been attacked so far, the terrorist threats received by the state of California to its main suspension bridges and the detailed shots of the Golden Gate and Brooklyn Bridges found among the possessions of terrorists captured in Spain indicate that bridge structures are being considered as potential targets by terrorist organizations (Williamson and Winget 2005). The terrorist threat on bridges, and on the transportation system as a whole, has been recognized by the engineering community and public officials, which resulted in the recent publication of a number of documents addressing this concern (see, for instance, FHWA 2003).

There is a need to develop bridge structural systems capable of

${ }^{1}$ Ph.D. Candidate, Dept. of Civil, Structural, and Environmental Engineering, Univ. at Buffalo, 206 Ketter Hall, Buffalo, NY 14260 (corresponding author). E-mail: fujikura@.buffalo.edu

${ }^{2}$ Director, MCEER and Professor, Dept. of Civil, Structural, and Environmental Engineering, Univ. at Buffalo, Buffalo, NY 14260. E-mail: bruneau@mceermail.buffalo.edu

${ }^{3}$ Profesor Auxiliar, Dept. de Ingenieria Estructural y Geotecnica, Macul, Pontificia Univ. Catolica de Chile, Santiago 782-0436, Chile. E-mail: dlg@ing.puc.cl

Note. Discussion open until April 1, 2009. Separate discussions must be submitted for individual papers. The manuscript for this paper was submitted for review and possible publication on June 26, 2007; approved on February 27, 2008. This paper is part of the Journal of Bridge Engineering, Vol. 13, No. 6, November 1, 2008. CASCE, ISSN 1084-0702/ 2008/6-586-594/\$25.00. providing an adequate level of protection against intentional blast loads. Any blast-resistant structural system must still be able to perform satisfactorily under all of the other loads acting on bridge structures. In this regard, it is interesting to note that there are some important similarities between seismic and blast effects on bridge structures: both major earthquakes and terrorist attacks are rare events, and, due to economic considerations, most of the energy imposed on structural members by these events is dissipated through inelastic deformations rather than being elastically absorbed. Given the fact that: (1) current codes require that bridge structures be designed for some level of seismic action in most states in the United States; and (2) blast and seismic loads often control the design, there is a need for structural systems capable of performing equally well under both seismic and blast loads.

This paper presents the results of a research project conducted to develop and experimentally validate such a multihazard bridge pier concept, i.e., a bridge pier system capable of providing an adequate level of protection against collapse under both seismic and blast loading, and whose structural, construction, and cost characteristics are not significantly different from those of the pier systems currently found in typical highway bridges in the United States. The proposed pier system is a pier-bent where concretefilled steel tube columns frame into beams made up of $\mathrm{C}$-shape steel sections embedded in the fiber-reinforced concrete foundation and pier cap.

The multihazard bridge pier-bent concept proposed in this study is intended for use in typical highway bridges. Although the terrorist threat to this type of bridges is usually assumed to be of lesser magnitude than that assigned to large signature bridges, the threat, especially to the ones strategically located, is nevertheless real and worthy of consideration (Winget et al. 2005). There are many possible courses of action by which terrorists might intend to destroy a bridge structure. The bridge pier-bent concept proposed was developed considering only one type of terrorist threat: the detonation of explosives located inside a small vehicle placed 
below the deck at close distance to the pier. Other possible courses of action, such as the detonation of hand-placed explosives and collisions using large vehicles, were not considered. Note that for security reasons, some key details of this blastrelated study are withheld from this paper. More specifically, the numerical values of some key quantities are not provided but presented in terms of parameters.

\section{Simplified Blast Analysis by Equivalent Single Degree of Freedom}

The simplified analysis procedure introduced in this study is commonly used in blast-resistant design. The analysis procedure considers an equivalent single-degree-of-freedom (SDOF) system having an elastic-perfectly plastic behavior, and assumes that all the energy imparted to the system by the blast loading is converted into internal strain energy. The key assumption of this analysis method is that real structures or components, which are multidegree of freedom systems, can be represented by a SDOF lumped-mass system (often called an equivalent SDOF system). Although this equivalent system cannot provide the detailed response of the structure, it is enough to calculate the response at one particular point of the structure; typically the point where the maximum deformation occurs in the system chosen for design. The equation of motion for an equivalent SDOF system is written as

$$
K_{\mathrm{LM}} M \ddot{x}+K x=P(t)
$$

where $K_{\mathrm{LM}}=$ load-mass factor, and $M, K$, and $P(t)=$ mass, stiffness, and load of the real structure, respectively. The load-mass factor, $K_{\mathrm{LM}}$, is obtained by equating the energies of the real structure and the equivalent SDOF system. Note that the damping component is typically neglected when calculating the response under blast loading since one cycle of response develops (Smith and Hetherington 1994; Mays and Smith 1995).

Structural response under blast loading depends on the response time of the structure relative to the duration of the explosion. The USDA (1990) categorized the relationship between these two parameters into three design ranges, which are impulsive load, pressure-time load (also called dynamic load), and pressure load (also called quasi-static load). For the cases considered herein, where the blast load duration is much shorter than the pier column's natural periods of response, the design will typically fall within the impulsive loading category. Therefore, the energy imparted to the structural system by blast loading is considered an impulsive loading. Using the equivalent SDOF analysis method, the maximum response to an impulsive load is obtained by assuming that all the energy imparted to the system by the blast loading is converted into internal strain energy. Accordingly, by equating the kinetic energy delivered by the impulse load and the strain energy stored in the elastic-perfectly plastic system, the maximum deformation, $X_{m}$, of the equivalent SDOF system due to impulsive-type blast loading is given by

$$
X_{m}=\frac{1}{2}\left(\frac{i^{2}}{K_{\mathrm{LM}} m r_{u}}+X_{E}\right)
$$

where $X_{E}=$ elastic deflection; $i=$ impulse; and $m$ and $r_{u}=$ mass and ultimate resistance of the column per unit length, respectively (Mays and Smith 1995).

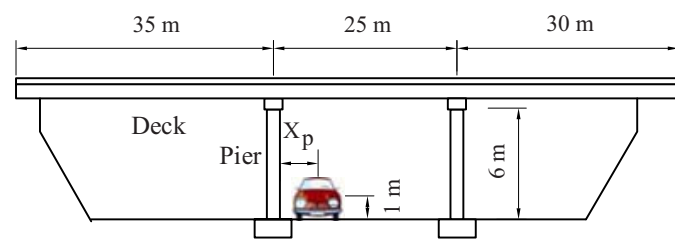

Fig. 1. Schematics of prototype bridge and assumed blast scenario

\section{Multihazard Design of Prototype Bridge Piers}

\section{Assumed Blast Scenario and Target Bridge Structure}

The blast scenario in this research is schematically illustrated in Fig. 1. The horizontal distance $X_{p}$ between the center of an explosive charge and the pier, referred to as standoff distance, was set based on what is found in typical highway bridges (the exact value is not indicated here for security reasons). The vertical distance between the center of an explosive charge and the ground was set equal to $1 \mathrm{~m}$ based simply on the geometry of typical car vehicles. Because of its very nature, it is difficult to accurately predict the explosive charge weight to be used in a terrorist attack. Reasonable estimates, however, can be made by taking into account some characteristics of terrorist actions. The explosive charge weight adopted in this study, referred to as $W_{p}$, in this paper, was set based on practical considerations (Williamson and Winget 2005), and was found to be very similar to the blast weights predicted in FEMA (2003) and in FHWA (2003) for terrorist actions.

The pier concepts considered were designed and analyzed assuming that they are part of a typical three-span continuous highway bridge described in Dicleli and Bruneau (1996) as shown schematically in Fig. 1. The span lengths are 35, 25, and $30 \mathrm{~m}$ (total length $L=90 \mathrm{~m}$ ). The width of the deck is $16 \mathrm{~m}$, the equivalent cross-section area of the deck is $0.592 \mathrm{~m}^{2}$, the equivalent moment of inertia of the deck (with respect to a vertical axis passing through the centroid) is $I_{D}=13.9 \mathrm{~m}^{4}$, the mass of the deck per unit length is $m_{D}=12.56 \mathrm{ts} / \mathrm{m}$, and the height of the columns is $H=6 \mathrm{~m}$. The total gravity load on each pier is assumed to be equal to $4,098 \mathrm{kN}$.

\section{CFST Columns Bridge Pier-Bent Concept}

Preliminary analysis and existing literature (e.g., Winget et al. 2005 ) indicate that the combined effects of spalling and cratering, and possibly breaching, control the design of substructure concrete members subjected to close-in blast loading. In this context, "spalling and cratering" refer to disengagement of the concrete at the back and front sides of the member, respectively, and "breaching" describes punching through the full concrete thickness (UFC 2004). The behavior of concrete members under blast loading could be substantially improved if these behaviors could be somehow prevented. In that perspective, encasing concrete in a steel shell would seem to be an adequate approach to provide blastresistant piers. The addition of steel jackets has been shown to be a viable strategy for the seismic retrofit of concrete bridge pier columns (Priestley et al. 1996). However, here, using such a jacket alone was calculated to be insufficient to provide adequate resistance to the large shear forces that develop at the base of piers subjected to blast loads. As such, using a fully composite concrete-filled steel tube continuous into the footing was found to be a more appropriate solution. Therefore, the pier concept con- 


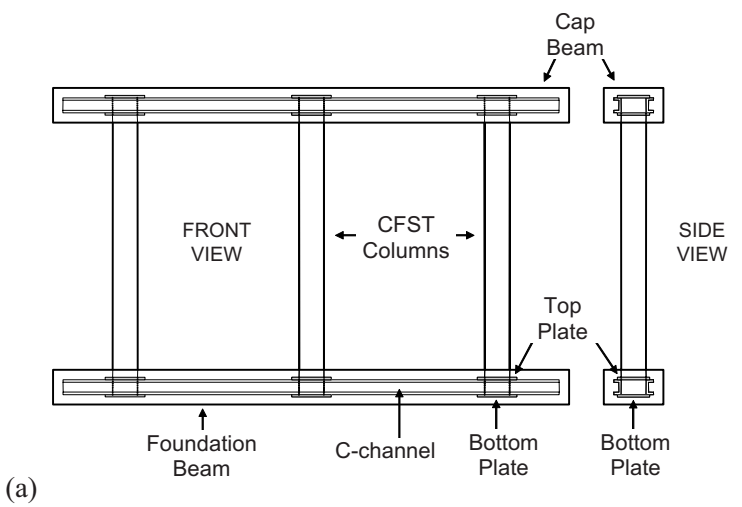

(b)

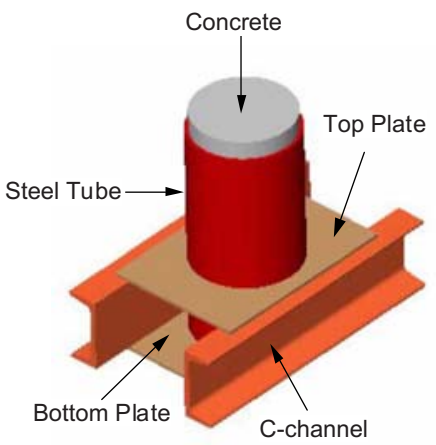

Fig. 2. Multicolumn pier-bent made up of CFST columns: (a) general description; (b) details of column-to-foundation beam connection

sidered in this study is a multicolumn pier-bent with concretefilled steel tube (CFST) column. Tests carried out by Marson and Bruneau (2004) for the purpose of seismic applications showed that CFST columns subjected to cyclic loading exhibit good energy-dissipation capabilities and stable hysteretic behavior up to a drift level equal to $7 \%$. A possible implementation of this concept is schematically shown in Fig. 2(a). The foundation beam consists of concrete-embedded C-channels linked to the columns through steel plates. This connection concept is schematically illustrated in Fig. 2(b). This type of foundation beam performed successfully in the tests by Marson and Bruneau (2004) in that it allowed the composite columns to develop their full moment capacity. Conceptually, the channels are designed to resist the full composite strength of the columns, and the concrete at the foundation beam does not need any reinforcement for strength purposes (fiber concrete is, however, recommended to prevent cracking of the concrete and subsequent water infiltration into the footing).

\section{Analysis for Blast Loading}

Assuming that breaching and spalling are not design considerations for CFST columns, the design of CFST columns subjected to blast loads is then governed by the magnitude of the allowable inelastic deformations under the expected blast pressures. The simplified analysis procedure introduced previously was adopted, in part, because it was judged that analysis refinements were not needed at this stage, and in part because little information was found about the actual distribution in space and time of blast pressures acting on circular columns subjected to close-in blasts. In this analysis, to calculate the maximum deformation by Eq. (2), the equivalent uniform impulse per unit length, $I_{\mathrm{eq}}$, is used for $i$ and calculated by

$$
I_{\text {eq }}=\beta D i_{\text {eq }}
$$

where $i_{\mathrm{eq}}=$ equivalent uniform impulse per unit area; $D=$ column diameter; and $\beta=$ factor to account for the reduction of pressures on the column due to its circular shape. Since the ratio of the pressure at a given angle of incidence to that at any other angle is not a constant but a function of the magnitude of the blast pressures, the value of $\beta$ is a function of both time and space. However, in order to simplify the analysis, it was decided to adopt a constant value of $\beta$. The values of blast pressures at different angles of incidence were obtained using the computer program AT-Blast (Applied Research Associates 2004) which is a public domain program for calculating the blast pressure and impulse from an explosive detonation. The resulting value of $\beta(=0.85)$ turned out to be very similar to the value adopted by Winget et al. (2005) for a similar analysis $(=0.80)$. The quantity $i_{\mathrm{eq}}$ was calculated by

$$
i_{\text {eq }}=\frac{\int_{0}^{H} i(z) \delta(z) d z}{\int_{0}^{H} \delta(z) d z}
$$

where $i(z)$ indicates the variation of impulse per unit area along the height of the column and $\delta(z)=$ normalized deflected shape of the column. In this analysis, $i(z)$ was taken as the envelope of maximum impulse (per unit area) at any time along the height of the column. Values of $i(z)$ were calculated using the program Bridge Explosive Loading (BEL) (USACE 2004). BEL generates airblast pressures considering reflections of the blast wave on the deck and on the ground. The resulting values of $i(z)$ are qualitatively shown in Fig. 3 along with peak pressure along the height of the column. The reduction of blast impulse due to the clearing time [i.e., the time required for the reflected portion of the blast wave to be cleared for the front face of the structure (Biggs 1964)] was not considered. Based on the analysis described in Winget et al. (2005), neglecting such pressure reduction due to "clearing time" is only slightly conservative.

The column was assumed fixed at the bottom but pinned at the top where bearings may not be able to prevent rotation of the cap beam about its longitudinal axis. For these boundary conditions, assuming that the in-span hinge develops at column midheight and both top and bottom of the column, the normalized deflected shape for inelastic deformations after plastic hinging is given as a
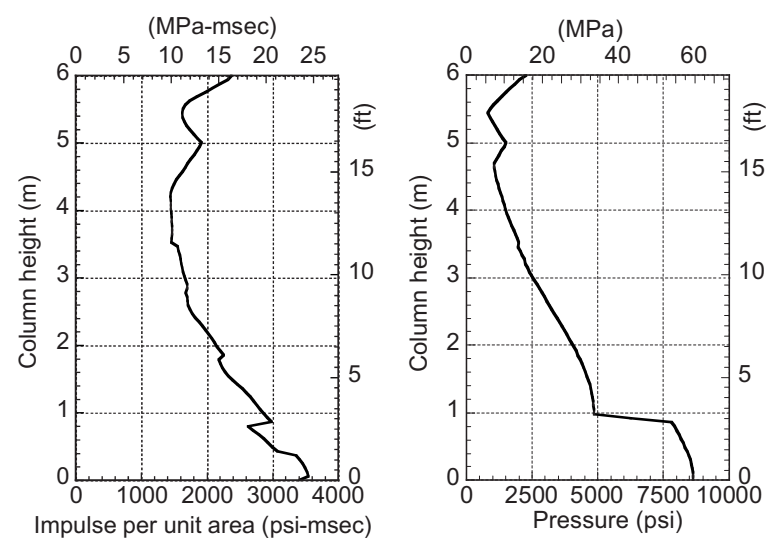

Fig. 3. Variation of total impulse and peak pressure along height of column 


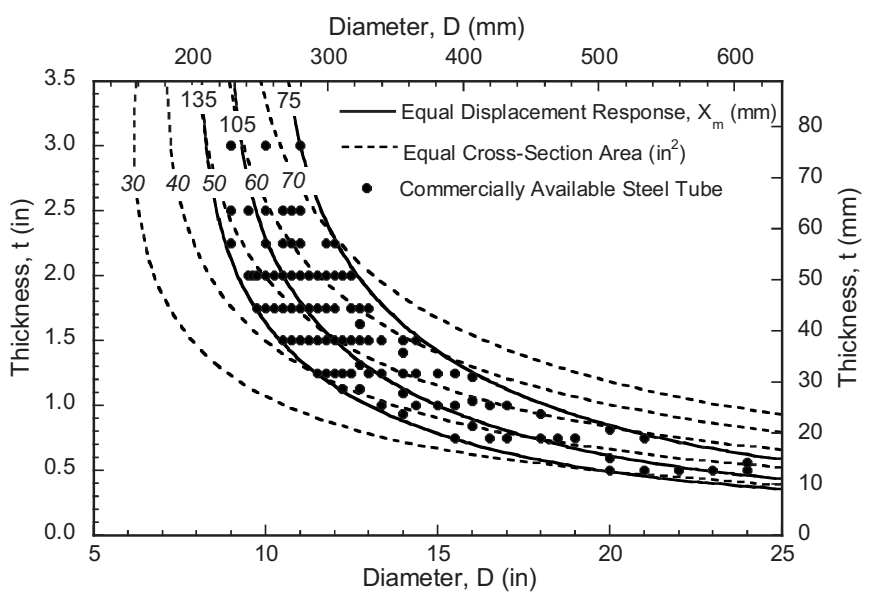

Fig. 4. Displacement response of CFST columns under blast load for cross sections of $30,40,50,60$, and $70\left(\right.$ in. $^{2}$ ) or equal displacement response of 75,105 , and $135(\mathrm{~mm})$ as function of various thicknesses and diameters of steel tubes

system of rigid-link members between those plastic hinges. For the boundary conditions and this deflected shape, the load-mass factor is $K_{\mathrm{LM}}=0.66$ and $r_{u}$ is given by $r_{u}=12 M_{p} / L^{2}$ where $M_{p}=$ plastic moment capacity of the column, which was calculated using the approximate equation presented in Bruneau and Marson (2004). Finally, $X_{E}$ is given by $X_{E}=r_{u} / K_{e}$ where $K_{e}$, the unit elastic stiffness of the equivalent SDOF system, is given by $K_{e}=160 E I_{e} / L^{4}$ (Mays and Smith 1995). The flexural stiffness of the column, $E I_{e}$, was calculated using the equation introduced in Eurocode 4 (Commission of the European Communities 1994) because the AISC provisions (AISC 1999) do not provide an equation for $E I_{e}$ (Bruneau and Marson 2004).

For the analysis, concrete strength, $f_{c}^{\prime}$, and Young's modulus, $E_{c}$, were assumed equal to 40 and $30,000 \mathrm{MPa}$, respectively. Young's modulus of steel was assumed equal to 200,000 MPa. Steel tube sections considered in the analysis included AISC round hollow structural sections, (HSS), AISC pipe sections, and several other sections provided by U.S. pipe manufacturers. Yield stress of steel was set equal to $290 \mathrm{MPa}$ for round HSS and equal to $240 \mathrm{MPa}$ for pipe sections. The above concrete strength and yield stress of steel were multiplied by 1.25 and 1.2, respectively, to account for strength magnification at large strain rates under impulsive conditions (Mays and Smith 1995).

Marson and Bruneau (2004) experimentally demonstrated that CFST columns of the type considered here had a cyclic rotation capacity of $0.07 \mathrm{rad}$. Therefore, for the monolithic loading condition considered here, it was conservatively assumed that the rotation capacity, $\theta_{u}$, of plastic hinges in CFST columns could be taken as $0.07 \mathrm{rad}$. For the assumed deflected shape of the column under blast load, the displacement capacity of the column, $X_{u}$, measured at column midheight, is then equal to $105 \mathrm{~mm}$. Note that the maximum rotation capacity reported by Marson and Bruneau (2004) was developed at the base of a cantilever. However, an in-span hinge can develop twice the plastic hinge length of a hinge at the base of a column. Thus, in hindsight, the midspan plastic rotation capacity at this stage could have been taken as $0.14 \mathrm{rad}$.

Displacement response of CFST columns under blast load is presented in Fig. 4 in which solid contour lines indicate equal displacement response, $X_{m}$, and broken contour lines show equal cross-section area. The displacement response for the commer- cially available steel tube sections whose response is between 75 and $135 \mathrm{~mm}$ is shown in Fig. 4 as individual data points (cases for which response falls outside that range are not plotted). The contours of $X_{m}$ considered in the figure were selected to represent the range of estimated ultimate displacement capacity. The plot shows that, for a fixed level of plastic rotation, the area of tube sections having a large $D / t$ ratio is less than the area of tube sections having a small $D / t$ ratio; hence material effectiveness was highest for piers having the highest diameter-to-thickness $(D / t)$ ratio. Results in Fig. 4 also show that, for the assumed blast load, the minimum thickness required is $13 \mathrm{~mm}$ (0.5 in.) for the range of diameters considered. Fig. 4 also indicates that the required diameter of tube sections having this minimum thickness is in the range of 508-610 mm (20-24 in.). Results shown in Fig. 4 indicate that CFST columns having practical dimensions are able to perform well under the assumed blast load, within the assumptions adopted for this analysis.

\section{Analysis for Seismic Load}

The response spectrum analyses were conducted for the proposed prototype pier-bent considering the $13 \mathrm{~mm}$ ( 0.5 in.) thick tube sections for diameters of $508 \mathrm{~mm}$ (20 in.) and $610 \mathrm{~mm}$ (24 in.). The bridge is assumed to be located in an area of moderate seismic activity. For analysis and design purposes, it is assumed that the corresponding pseudoacceleration $\left(S_{A}\right)$ response spectrum has a peak acceleration of $2.50 A_{g}$ (peak ground acceleration, $A_{g}$ $=0.3 \mathrm{~g}$ ) and varies as a function of $1 / T$ in the long period range. The spectral shape of the response spectrum is typical of rock or very stiff soil foundations. In a longitudinal direction, assuming that the bearings supporting the end spans at the abutments do not restrain displacements in the longitudinal direction, longitudinal stiffness and strength are then only provided by the pier. The bridge has two pier-bents as shown in Fig. 1, and each pier-bent is assumed to have three CFST columns fixed at the foundation level and pined at the cap-beam. In a transverse direction, assuming that the bearings at the abutments remain elastic and can laterally restrain the bridge spans, the deck is modeled as a flexural member pinned at the ends, and the pier-bents are modeled as springs of lateral stiffness. The resulting ductility demand ratios were 2.56 and 2.47 for the columns with diameters of 508 and $610 \mathrm{~mm}$, respectively in a longitudinal direction, and 0.84 and 0.95 for the columns with diameters of 508 and $610 \mathrm{~mm}$, respectively, in a transverse direction, while they remained elastic for excitation in a transverse direction due to the large deck stiffness (the abutments resisting all the lateral loads). These calculations show that, for the prototype considered, the tube sections selected to provide satisfactory performance for the blast load considered also provide adequate lateral load resistance for the seismic load. Note that although seismic considerations are presented subsequently to blast considerations in this paper, during the design process, both conditions were accounted for simultaneously; some iterations were required to obtain a design satisfying all constraints.

\section{Experimental Specimens}

Two identical multicolumn bents, Bent 1 and Bent 2, were fabricated and a series of blast tests were performed at the U.S. Army Corps of Engineers Research Facility in Vicksburg, Miss. Due to constraints with the maximum possible blast charge weight that could be used at the test site and specimen cost considerations, 


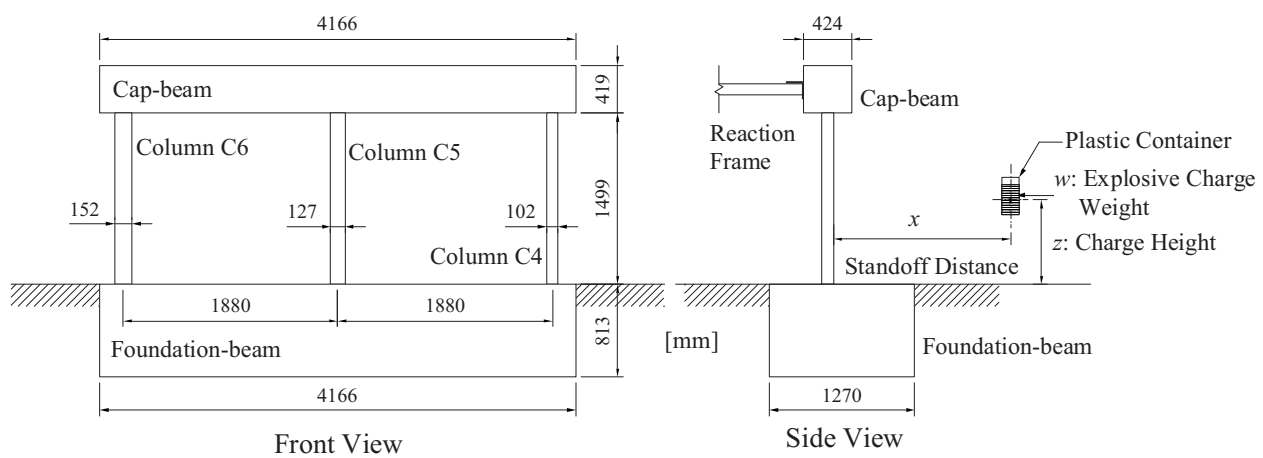

Fig. 5. Experimental specimens and explosive charge situation

test specimen dimensions were set to be $1 / 4$ scale of the prototype bridge piers. Experimental specimens are shown in Fig. 5 along with an explosive charge situation. Each specimen consists of three piers with different diameters: $D=102 \mathrm{~mm}$ (4 in.), $127 \mathrm{~mm}$ (5 in.) and $152 \mathrm{~mm}$ (6 in.) (labeled hereafter as Column B1-C4, B1-C5, and B1-C6, respectively, for Bent 1 and Column B2-C4, B2-C5, and B2-C6, respectively, for Bent 2), connected to steel beams embedded in the cap beam and a foundation beam. Fig. 6 shows a general photograph of the specimens' setup. The bent frames were braced in what would correspond to the bridge longitudinal direction at the level of the cap beams. A reaction frame was built for this purpose. The cap beams were not connected to the frame but in contact with the frame, such as to support the force from the cap beam. This allowed for properly modeling the longitudinal fixity provided by the inertia effect of the superstructure without preventing rotation at the top of the bent.

\section{Design of Specimens}

The selection of the column specimens was done according to the pier concept proposed previously. As described earlier, the prototype design pipe diameter is in the range of $508-610 \mathrm{~mm}$ (20-24 in.) with a minimum thickness of $13 \mathrm{~mm}$ (0.5 in.) for the assumed blast load corresponding to a credible threat. Therefore, considering test specimen dimensions at $1 / 4$ scale, diameters of $102 \mathrm{~mm}$ (4 in.), $127 \mathrm{~mm}$ (5 in.), and $152 \mathrm{~mm}$ (6 in.) and thickness of $3.2 \mathrm{~mm}(0.125 \mathrm{in}$.) were selected as the column sections. The plastic moment of the column specimens was calculated using the material properties and dynamic strength magnification

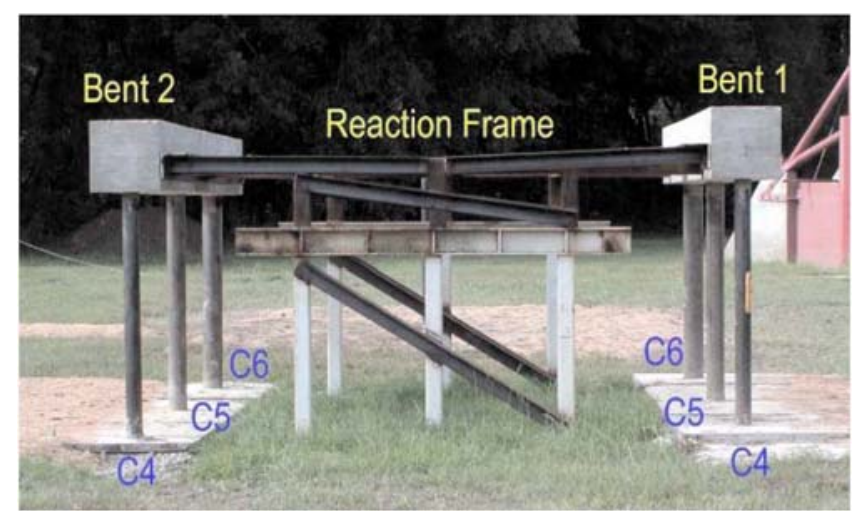

Fig. 6. Test setup factors presented in the prototype bridge design. The resulting plastic moment, $M_{p}$, of the column specimens was $12.2,19.1$, and $27.4 \mathrm{kN} \mathrm{m}$ for $\mathrm{C} 4, \mathrm{C} 5$, and $\mathrm{C} 6$, respectively.

As shown in Fig. 2(b), the foundation beam and cap-beam consist of concrete-embedded C-channels linked to the columns through steel plates. The foundation beam was designed such that the moment demand on the C-channels was assumed equal to the plastic moment capacity of the largest CFST column (i.e., Column C6). The cap beam was designed to remain elastic when subjected to blast pressures acting upwards on its underside. C-channel $C 4 \times 7.25$ and $C 12 \times 30$ of A 36 steel were selected for the foundation beam and the cap beam, respectively. All top and bottom plates were $4.8 \mathrm{~mm}$ (0.1875 in.) thick of A 36 steel. This particular foundation design is not an issue for the purpose of this test program. Other competent approaches that can resist the full composite strength of the composite column would also be adequate.

\section{Materials}

The steel for all circular columns, HSS $4.0 \times 0.125$ (Column C4), HSS $5.0 \times 0.125$ (Column C5), and HSS $6.0 \times 0.125$ (Column C6), was specified to be ASTM A500 Grade B. Coupons were cut out from the specimens after the blast tests. Since the columns were partially damaged due to the tests, coupons were cut off from sides of the columns that were subjected to less strain (and presumably remained elastic). The measured yield strengths of the steel tubes were 357,254 , and $419 \mathrm{MPa}$ and the measured Young's moduli were 188,041, 178,793, and 196,179 MPa for C4, C5, and C6, columns, respectively. The compressive strength for the concrete used in the CFST was obtained from compression tests of concrete cylinders. Average compressive concrete cylinder strengths at 28 days were 42.0 and $30.0 \mathrm{MPa}$ for column and cap beam, and footing, respectively. Concrete compressive strength of circular columns on the day of blast load testing was predicted by the relationships proposed by ACI Committee 211 (1992) since cylinder tests were not conducted on the test day. The predicted compressive strengths on the test day were 43.2, 43.4, and 43.5 MPa for Column B1-C4 and B1-C6, Column B1-C5 and B3-C4, and Column B2-C6 and B2-C5, respectively.

\section{Experimental Cases}

A summary of the experimental cases is presented in Table 1 along with test and analytical results. Exact values of charge weights and standoff distances are normalized and expressed in 
Table 1. Summary of Experimental Cases, and Test and Analytical Results

\begin{tabular}{|c|c|c|c|c|c|c|c|c|c|c|}
\hline \multirow[b]{2}{*}{ Test number } & \multirow[b]{2}{*}{ Column } & \multirow[b]{2}{*}{ Objective } & \multicolumn{3}{|c|}{ Explosive parameters } & \multirow{2}{*}{$\begin{array}{c}\text { Test } \\
X_{\text {test }} \\
(\mathrm{mm})\end{array}$} & \multicolumn{4}{|c|}{ Analysis } \\
\hline & & & $w$ & $x$ & $\begin{array}{c}z \\
(\mathrm{~m})\end{array}$ & & $\beta$ & $\begin{array}{c}X_{E} \\
(\mathrm{~mm})\end{array}$ & $\begin{array}{c}X_{m} \\
(\mathrm{~mm})\end{array}$ & $\begin{array}{c}X_{m}-X_{E} \\
(\mathrm{~mm})\end{array}$ \\
\hline 1 & $\mathrm{~B} 1-\mathrm{C} 4$ & Preliminary & $0.1 W$ & $3 X$ & 0.25 & 0 & - & - & - & - \\
\hline 2 & $\mathrm{~B} 1-\mathrm{C} 4$ & Maximum deformation & $0.55 \mathrm{~W}$ & $3 X$ & 0.75 & 0 & - & - & - & - \\
\hline 3 & $\mathrm{~B} 1-\mathrm{C} 4$ & & W & $2 X$ & 0.75 & 30 & 0.472 & 6 & 36 & 30 \\
\hline 4 & B1-C6 & & $W$ & $1.1 X$ & 0.75 & 46 & 0.458 & 4 & 50 & 46 \\
\hline 5 & $\mathrm{~B} 1-\mathrm{C} 5$ & & $W$ & $1.3 X$ & 0.75 & 76 & 0.447 & 3 & 79 & 76 \\
\hline 6 & $\mathrm{~B} 2-\mathrm{C} 4$ & & $W$ & $1.6 X$ & 0.25 & 24 & 0.465 & 10 & 34 & 24 \\
\hline 7 & $\mathrm{~B} 2-\mathrm{C} 4$ & Fracture of steel shell & $W$ & $0.6 X$ & 0.25 & 395 & - & - & - & - \\
\hline 9 & B2-C6 & & $W$ & $0.8 X$ & 0.25 & 45 & 0.440 & 6 & 51 & 45 \\
\hline 10 & $\mathrm{~B} 2-\mathrm{C} 5$ & & $W$ & $0.8 X$ & 0.25 & 100 & 0.417 & 5 & 105 & 100 \\
\hline
\end{tabular}

functions of $W$ and $X$, respectively. Owing to some uncertainty such as response of the cap beam and behavior of concrete in the cap beam subjected to blast load, the blast charge in the first test, Test 1, was selected to ensure that Column B1-C4 responded within the elastic range. Tests $2-6$ and Tests 7,9 , and 10 were intended to induce specific target maximum deformations and their ultimate limit state, respectively. Three parameters were considered in deciding test conditions, height of charge, $z$, standoff distance, $x$, and weight of charge, $w$, as schematically shown in Fig. 5. Height was chosen either to be a lower height ( $h$ $=0.25 \mathrm{~m})$ or a middle height $(h=0.75 \mathrm{~m})$ case. Lower height represented the height from the assumed blast scenario, which was $1 \mathrm{~m}$ for the prototype bridge. Middle height corresponds to the midheight of the bridge column and, even though an unlikely position for an actual threat, was chosen because it was expected to provide the most severe damage to a column and the symmetric damage pattern as a first simple case to consider. The maximum deformation caused by the explosion was predicted using the concept of impulsive response presented previously. The maximum rotation capacity was set to be $0.14 \mathrm{rad}$ at the middle span of the column for the cases with charges at midheight, and $0.07 \mathrm{rad}$ at the bottom of the column for the charges located at the lower height. The target deformations for the midheight cases (Tests 2-5) and lower height case (Test 6) were 53 and $18 \mathrm{~mm}$, respectively.

Although Test 2 was originally intended to induce inelastic deformations, there was no damage to Column $\mathrm{B} 1-\mathrm{C} 4$, as the column again responded within the elastic range. To obtain inelastic deformations, the predetermined testing program had to be revised-new test cases were developed by increasing blast charge, $w$, or/and decreasing standoff distance, $x$. As such, blast charge was increased to the maximum value $W$ from $0.55 \mathrm{~W}$ and standoff distance was decreased to $2 X$ from $3 X$ in Test 3 . On the basis of the results of Test 3 in which inelastic deformations were obtained, the calculation procedure to predict column deformations was revised. To account for the reduction of effective pressures due to the circular shape of columns, a reduction factor $\beta$ was proposed in Eq. (3), and a value of 0.85 was adopted for Test 2 following the design procedure presented previously. However, that 0.85 value was found to be too conservative on the basis of the test results. As a first step (by trial and error), by backcalibration of the calculated maximum deformation, $X_{m}$, with the maximum deformation, $X_{\text {test }}$, of Test 3 , a new estimated value of $\beta$, was calculated to be 0.38 . This factor of 0.38 was used to recalculate the blast charge parameters for all the remaining column tests. The blast charge parameters shown in Table 1 are the recalculated values based on this factor of 0.38 , and these param- eters are the ones actually used in the tests. In hindsight, the test results, $X_{\text {test }}$, had to be compared with the calculated residual deformations whose values were $X_{m}-X_{E}$ instead of $X_{m}$ since the maximum deformations measured after the tests were obtained without loading on the structure (i.e., after the blast load) and are actually residual plastic deformations. This factor will be discussed in detail in a subsequent section. As Tests 4,5 , and 6 provided sufficient data on the ability to match the predicted target deformations, Tests 7, 9, and 10 were conducted in an attempt to push the columns to their ultimate limit state, namely fracture of the steel tube, due to excessive plastic rotation. Standoff distance and charge weight for Tests 7, 9, and 10 were arbitrarily decided to achieve the onset of fracture of the steel tube based on the previous experimental results, such as the observed maximum rotations of the columns and the calibrated factor $\beta$ in Eq. (3).

\section{Experimental Results}

\section{Experimental Observations}

Maximum deformations of Tests 3-5 (midblast height cases) as shown in Table 1 were observed at the same height as the blast charge. Fig. 7(a) shows Column B1-C5 after Test 5. Many pits and a notch were observed on the surface of the column around the height of the blast charge, as seen in Fig. 7(b). These marks can be attributed to debris impacts, particularly to the disk attached at the midheight of the blast charge container as it hit the

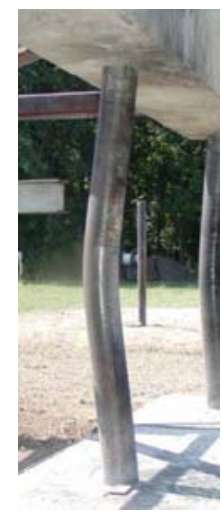

(a)

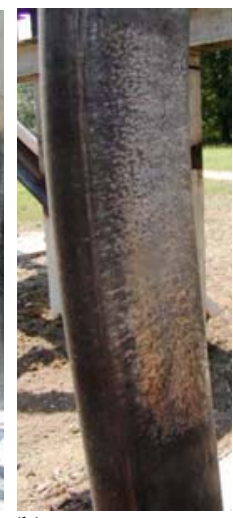

(b)

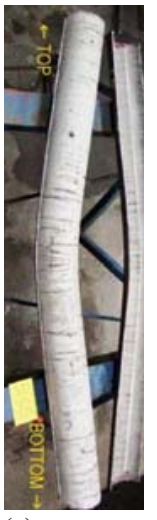

(c)
Fig. 7. Column B1-C5 after Test 5: (a) column deformation; (b) column surface around midheight; and (c) core concrete 

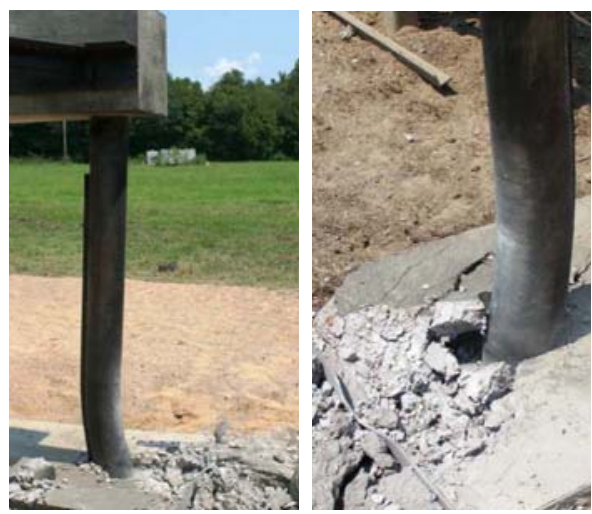

(b)

Fig. 8. Specimen after Test 9: (a) column deformation; (b) foundation

column during the explosion, but these minor local effects had no impact on the results. No spalling of the concrete was observed at the cap beam and foundation beam as a result of the blast pressures. Inspection of core concrete after removal of half of the steel shell [Fig. 7(c)] showed that cracks occurred at column midheight on the tension side. In addition, some cracks developed at both the top and bottom of the column on the tension side of the negative moment region due to the rigid boundary conditions. It should be added that although the cap beams were not fixed to the reaction frames, the rotation of the cap beam was partly restrained by the torsion resistance of the cap beam and the other two columns in the pier-bent.

Test 7 was conducted as a retest of Column B2-C4, which had already experienced inelastic deformations in Test 6 . The column was blown up from the bent by the explosion. In Tests 9 and 10, the blast charge was set on the side of the bent rather than on the front. This was done because it was desired to investigate a boundary condition at the top of the columns different from the one for Tests 1-7. Therefore, the column boundary condition in Tests 9 and 10 was considered to be rigid, i.e., fixed-fixed. Figs. 8( $\mathrm{a}$ and $\mathrm{b}$ ) show Column B2-C6 after Test 9 and the damage to the foundation beam. Fig. 9(a) shows Column B2-C5 after Test 10. Buckling of the steel tube was observed near the height where maximum deformation occurred as seen in Fig. 9(c). The fracture of the steel was observed halfway around the base of the column as shown in Fig. 9(b). The crater into the foundation reached the embedded C-channel connection.
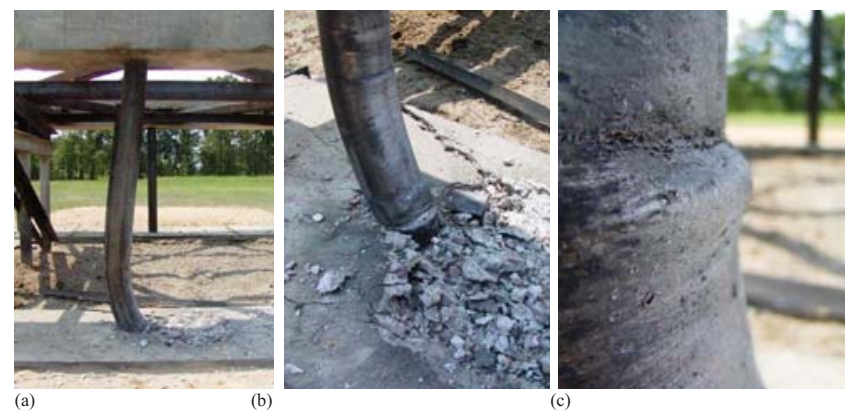

Fig. 9. Specimen after Test 10: (a) column deformation; (b) foundation; and (c) buckling furnace

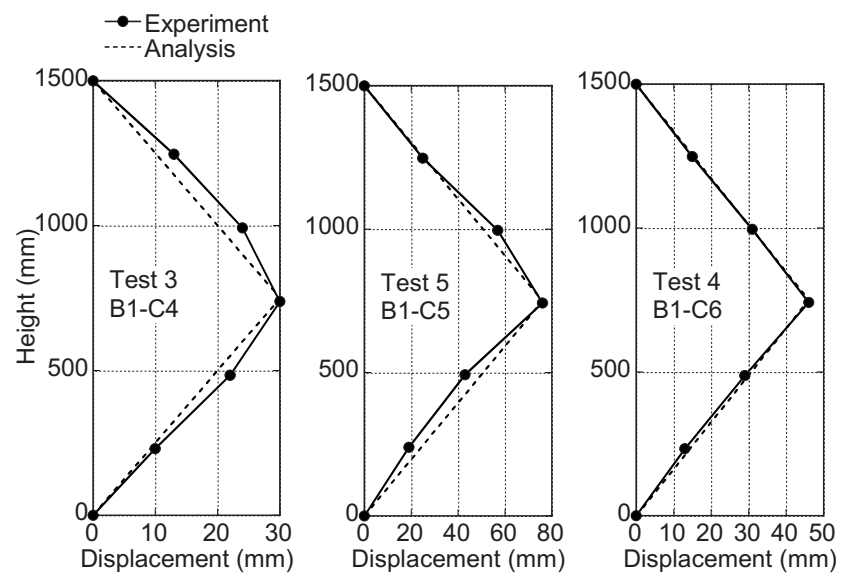

(a)
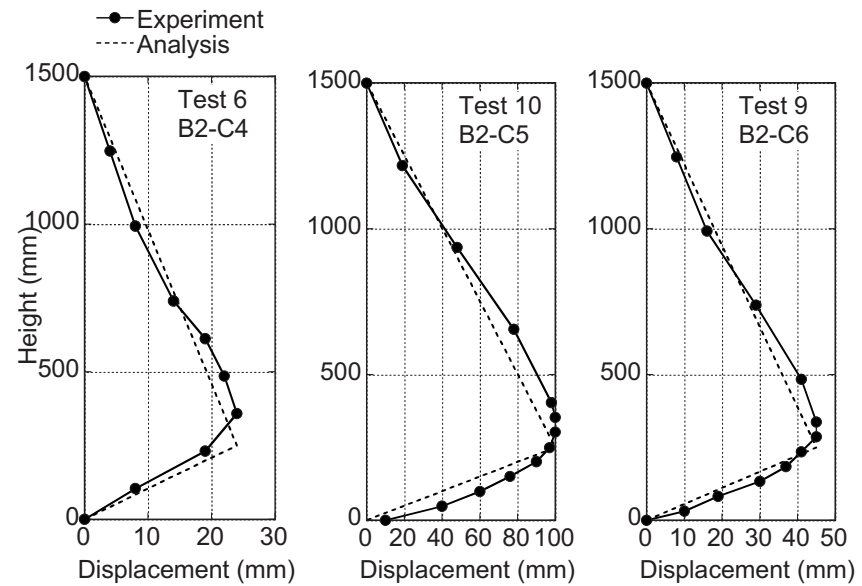

(b)

Fig. 10. Comparison of experimental column deformations with analysis: (a) explosion at midheight; (b) explosion at low height

\section{Deformation of Columns}

The concept of equivalent uniform peak impulse was introduced to model the blast impulse applied to an equivalent SDOF system given by Eq. (4). The assumed deformed shape $\delta(z)$ must closely match the actual deformation of the column for the equivalent impulse to be accurate. The deformations of the columns obtained from the test cases, for which residual plastic deformations were obtained, were compared with the analytical ones. In the analytical model, plastic hinges (rigid-plastic model) are assumed to occur at the top and bottom of each column and at the height of the blast charge. Figs. 10(a and b) compare the corresponding experimentally and analytically obtained deformations for explosions at midheight and low height, respectively. As shown in Fig. 10 , the assumed deflected shapes approximately match the obtained deformations. This confirms that, for the simplified analysis, the deformed shape could be assumed to be linear between rigid-plastic hinges and that the maximum deformation can be reasonably assumed to occur at the height of the explosion. Since the blast tests were carried out without an axial force representative of the gravity loads, secondary moment effects were analytically examined for each of the test columns. The second-order analysis showed that the deformed columns subjected to blast load were stable against $P-\delta$ failures for the axial force considered. 


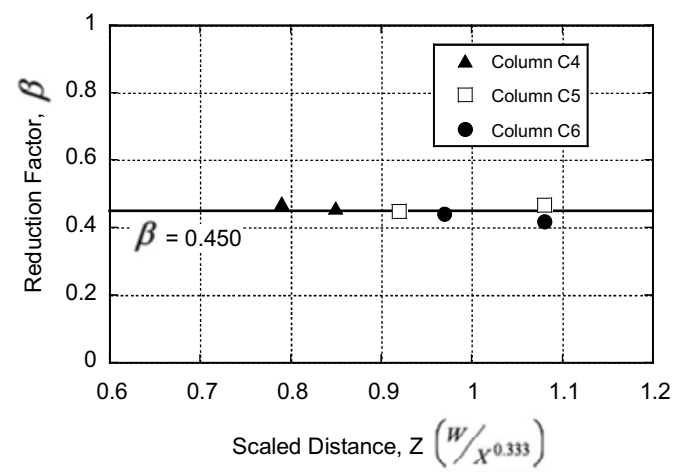

Fig. 11. Reduction factor

\section{Comparison with Simplified Analysis for Column Tests}

Experimentally obtained maximum plastic deformations of the piers were compared with the ones that can be calculated using simplified method of analysis. These simplified analyses were conducted using the strength values obtained from the compression tests of concrete cylinders and the tensile tests for the steel tubes. Following the approach presented previously by calibrating the analysis with the test results, revised values of $\beta$ for each test were calculated using Eqs. (2) and (3). Note that the column was assumed fixed at the bottom and the top instead of pinned at the top due to the constraint of the cap beam and the other columns in the pier-bent observed from the test results. The resulting values for $\beta$ are presented in Table 1 for the six test cases for which residual plastic deformations were obtained, along with the calculated elastic maximum deformations, $X_{E}$, and the calculated maximum deformations under blast loadings, $X_{m}$. These values of $\beta$ were plotted by the scaled distance, $Z$, which is defined by $Z$ $=w / x^{0.333}$ in Fig. 11 (Mays and Smith 1995). It was found that the value of $\beta$ for this type of circular columns is 0.45 (i.e., mean value of 0.450 and standard deviation of 0.020 from the six samples considered). This value is more appropriate than 0.85 used for the preliminary calculations because it accounts for the close-in blast effect, clearing effect, and assumption of strain rate effect.

\section{Damage Progress of Columns}

By sequencing the tests results as a function of increasing charge, the progress of damage along a typical column is presented in Fig. 12 for the blast charge located at low height. Although results presented in these figures are for columns having different diameters, they provide useful information on how the deformation of a column relates to the extent of damage. Results are presented corresponding to these damage states, namely: (1) plastic deformation; (2) onset of fracture of the column; and (3) postfracture of the column. In each case, column deformations are shown along with the rotation at supports and maximum deformation, and the crack patterns of core concrete are sketched based on the observation of the core concrete performed after the test. Fig. 12 (3) shows the deformations obtained in Column B2-C5 at the onset of fracture. For that case, this limit state was observed to develop at a plastic rotation angle of approximately $0.297 \mathrm{rad}$ $\left(17.0^{\circ}\right)$ at the bottom support. It can be speculated that the plastic rotation angle for that limit state would have been similar for the other columns. Fig. 12 (4) shows the case for which the steel tube fractured fully. In this case, it is assumed that the complete fracture first occurred at the bottom end of the column. After it fractured under the applied pressures, the column behaved as a

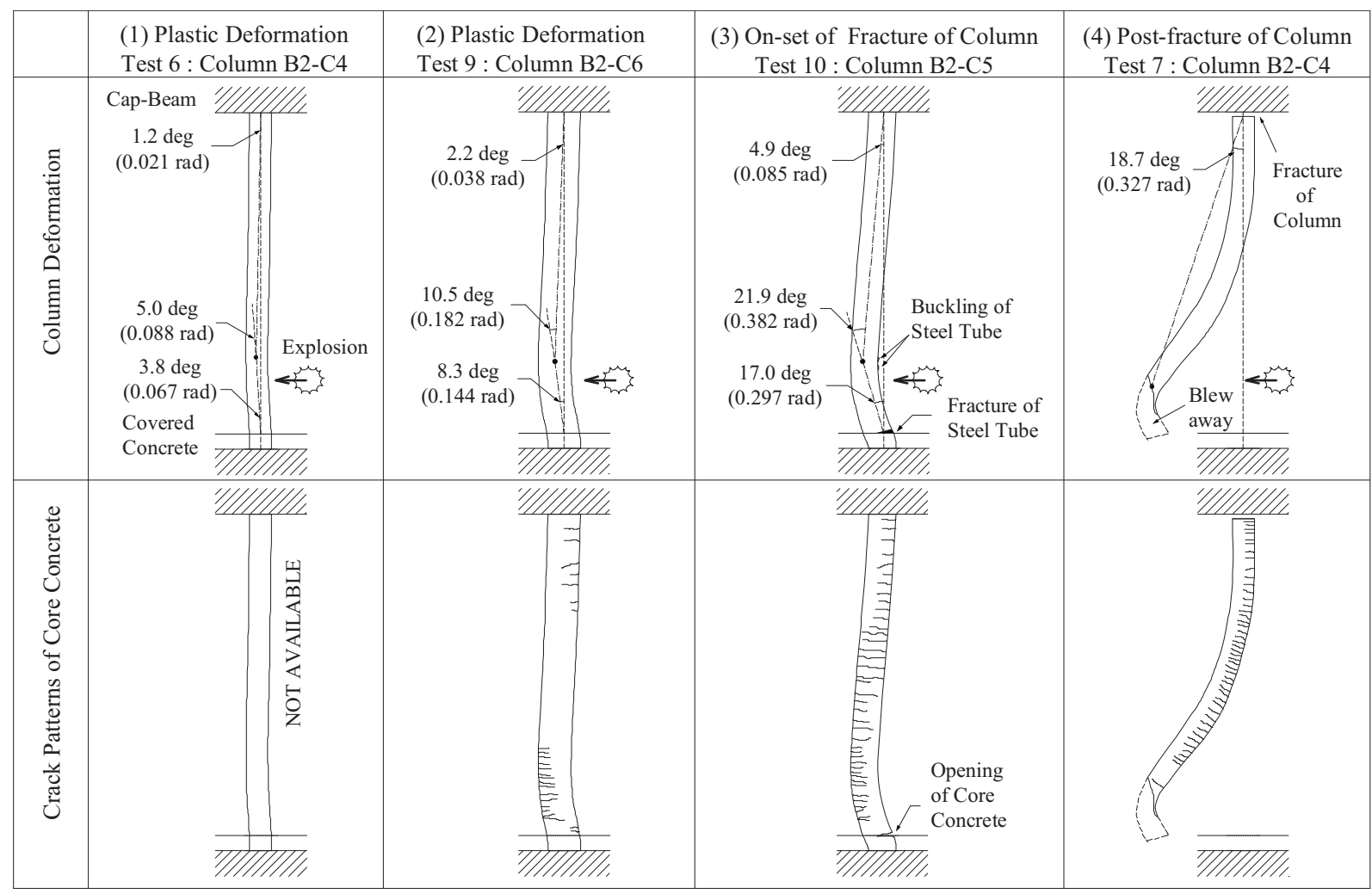

Fig. 12. Damage progress of column (blast at low height) 
cantilever suspended from the top. Therefore, it developed the curvature in a direction reverse to what was observed for the other columns. Then, it eventually fractured at the top as this column was projected outside of its setup under the blast forces. One could approximate the plastic rotation that occurred when the top ruptured to be $0.327 \mathrm{rad}\left(18.7^{\circ}\right)$ by the procedure graphically shown in Fig. 12 (4).

\section{Conclusions}

A multi hazard bridge pier concept consisting of CFST columns to protect bridges from seismic and blast loading has been developed and experimentally validated. It is effective for blast resistance because breaching and spalling of concrete are prevented from occuring in CFST columns. Tubes having the thicknesses and diameters required for CFST columns to perform well under the assumed blast load and seismic excitations are readily available. The specimens tested were designed per a simplified method of analysis that considered an equivalent SDOF system having an elastic-perfectly plastic behavior and assuming that all the energy imparted to the system by the blast loading is converted into internal strain energy. Blast tests showed that CFST columns of bridge pier specimens exhibited a satisfactory ductile behavior under blast loading. The foundation connection concept applied in this experiment allowed us to develop the composite strength of CFST column under blast loading. Comparison of the results from the blast tests with the results predicted by this simplified analysis showed that the blast effective pressures acting on a circular column are equal to 0.45 of those acting on a flat surface.

\section{Future Research}

Future research is desirable to investigate the adequacy of finiteelement models to better understand the behavior of the system. The data provided by this experimental program could be used to calibrate these finite-element models, which could then be used for extended parametric studies. Future research could also investigate the performance of regular reinforced concrete columns or of reinforced concrete columns jacketed by steel shells taking advantage of the effective pressure factor derived in this research.

\section{Acknowledgments}

This research was conducted by the University at Buffalo and was supported by the Federal Highway Administration under Contract No. DTFH61-98-C-00094 to the Multidisciplinary Center for Earthquake Engineering Research. This support is gratefully appreciated. However, any opinions, findings, conclusions, and rec- ommendations presented in this paper are those of the writers and do not necessarily reflect the views of the sponsors. Special thanks are given to James C. Ray at the Eng. Research and Dev. Center of the USACE for his help and assistance in the logistics of the experiments.

\section{References}

American Concrete Institute (ACI). (1992). "Standard practice for selecting proportions for normal, heavyweight, and mass concrete." $A C I$ manual of concrete practice, Committee 211, Detroit.

American Institute of Steel Construction (AISC). (1999). LRFD specifications for structural steel buildings, Chicago.

Applied Research Associates, Inc. (2004). Antiterrorist blast, version 2.1, (AT-Blast), Albuquerque, N.M.

Biggs, J. M. (1964). Introduction to structural dynamics, McGraw-Hill, New York.

Bruneau, M., and Marson, J. (2004). "Seismic design of concrete-filled circular steel bridge piers," J. Bridge Eng., 9(1), 24-34.

Dicleli, M., and Bruneau, M. (1996). "Quantitative approach to rapid seismic evaluation of slab-on-girder steel highway bridges." J. Struct. Eng. (India), 122(10), 1160-1168.

Commission of the European Communities. (1994). "Design of composite steel and concrete structures." Eurocode 4, Brussels, Belgium.

Federal Emergency Management Agency (FEMA). (2003). Reference manual to mitigate potential terrorist attacks against buildings, FEMA 426, Washington, D.C.

Federal Highway Administration (FHWA). (2003). Recommendations for bridge and tunnel security, Prepared by the Blue Ribbon Panel on Bridge and Tunnel Security, Washington, D.C.

Marson, J., and Bruneau, M. (2004). "Cyclic testing of concrete-filled circular steel bridge piers having encased fixed-based detail." $J$. Bridge Eng., 9(1), 14-23.

Mays, G. C., and Smith, P. D. (1995). Blast effects on buildings, Telford, London.

Priestley, M. J. N., Seible, F., and Calvi, G. M. (1996). Seismic design and retrofit of bridges, Wiley, New York.

Smith, P. D., and Hetherington, J. D. (1994). Blast and ballistic loading of structures, Butterworth-Heinemann, Stoneham, Mass.

Unified Facilities Criteria (UFC). (2004). Basic guidelines for chemical hardening of new military facilities, UFC 3-340-13, Department of Defense, Washington, D.C.

U.S. Army Corps of Engineers (USACE). (2004). Bridge explosive loading, Version 1.1.0.3, (BEL), Engineer Research and Development Center, Vicksburg, Miss.

U.S. Department of the Army (USDA). (1990). Structures to resist the effects of accidental explosions, Technical Manual TM 5-1300, Washington, D.C.

Williamson, E. B., and Winget, D. G., (2005). "Risk management and design of critical bridges for terrorist attacks.” J. Bridge Eng., 10(1), 96-106.

Winget, D. G., Marchand, K. A., and Williamson, E. B. (2005). “Analysis and design of critical bridges subjected to blast loads." J. Struct. Eng. (India), 131(8), 1243-1255. 